\title{
EDITORIAL
}

\section{OR as innovation}

In an increasingly turbulent and competitive environment, it is something of a cliché to suggest that organizations need to become more adaptable and innovative if they are to succeed in the future. Product innovation is an obvious aspect of this requirement, but often just as important is innovation in organizational processes, which give rise to greater efficiency, cost savings, or the freeing of scarce resources to deploy on a broader range of activities. These innovations need not be of a large-scale, radical kind. Various researchers have pointed out the significant contribution to commercial success of small incremental innovations in both products and processes.

Most if not all OR is aimed at incremental process innovation. The OR contribution may be to provide the innovation itself, such as a new decision support or information system, or to provide analysis to help design an innovation, such as an inventory reduction plan or reorganization. Product innovation within the OR function leads to the provision of an enhanced service to clients, for example in offering techniques for forecasting or investment appraisal.

The growing interest in organizational innovation has led to a burgeoning literature concerned with the successful management of innovation. Now this should be of great interest to operational researchers, because of the potential overlap of concerns with OR practice. The general management orientation of the innovation literature raises the real possibility of new insights for the OR practice as innovative activity. But conversely there may be scope for exploiting OR expertise in a more overtly innovation-oriented packaging.

Much depends on how closely OR interventions resemble the generic innovation process. A typical description of the innovation process is Lemaitre and Stenier's four-stage model summarised in Figure 1. Implicit in each stage is the gathering of data in three areas: technical, commercial and organizational, together with a recognition that feedback loops may occur. In particular, development may involve a series of trial-and-error approximations with a prototype, or necessitate returning to the conceptualization phase to revise the entire concept. In the context of OR, all this looks rather familiar. However, one interesting difference between this process model and typical OR process models is that in the innovation process model the "perception" and "conceptualization" stages receive much more emphasis, whereas OR process models tend to focus on a more detailed characterization of the "development" stage. Although "perception" and "conceptualization" must be important precursers to all OR projects, there is very little discussion of these stages in the OR literature. Creativity, the generation of new ideas, and the nurturing of these are at the heart of OR, but one would need to turn to the innovation literature for guidance on improving organizational practice in these areas.
Figure 1: Stages in the innovation process
Perception
- vague idea
- build support for idea
- decision to let project go ahead
Conceptualization • elaboration of idea
- project proposal drawn up
- approval for project sought - if accepted then action plan drawn up
Development
- definition of conditions of technical feasibility
- consideration of commercial viability and organization integration
- decision to proceed with innovation on a larger scale, or not
Operationalization • integration into everyday activities of organization (investment in equipment, training, information systems)

Much of the innovation literature is concerned with identifying the factors which influence an organization's capacity to innovate, usually based on empirical study of a number of innovation projects (for example: Lemaitre and Stenier [130 innovations]; Marquis [570 innovations]). Lemaitre and Stenier's study identifies a useful list of factors to consider in each stage of the innovation process, in particular the perception and conceptualization stages.

\section{Perception}

A key concern at this stage is the stimulation of an environment conducive to the generation, receipt and development of new ideas. Factors that help to create such an environment include: sufficient slack resources (information and time); ability to anticipate crises which call for rapid innovation; "newcomers" who can bring a fresh view; and specific organizational structures to handle and manage new ideas. The OR group fits neatly into this context provided there is a clear brief and motivation actively to search for new ideas. The issue of the position of the OR group in the organization is pertinent here. The scope and opportunity for innovative intervention is likely to be very different for a group forming part of a business development division and a group situated in computer or management services

In respect of the generation of original ideas, recognition of demand appears to be a more frequent factor in successful innovation than the recognition of technical potential. For example, of the 570 innovations studied by Marquis, three-quarters were stimulated by a market demand or production need; only one-fifth arose from recognition of the potential of a technical idea. An obvious conclusion, says Marquis, is that "innovative management ought to concentrate on any and all the ways of analysing such demands and needs. For example, more effective communication should be established amongst specialists in sales, marketing, 
production and $R \& D$ to see that such opportunities are not overlooked.". Quinn makes a similar point: innovative companies exhibit a strong market orientation at the very top of the company, and have mechanisms to ensure interactions between technical and marketing people at lower levels. In the most innovative companies in Quinn's sample, managers focused primarily on seeking to anticipate and solve customers' emerging problems. For the innovative OR group, these findings suggest looking beyond current concerns of (potential) in-house clients, and seeking to understand the developing needs of the client's customers (whether internal or external). Secondments of OR personnel to client departments can be one way to develop this understanding in-depth, and ought to involve formal reports or presentations by the secondee throughout the secondment period. Developing a routine dialogue with one particular part of the organization may be beneficial for understanding a (potential) client's and their customers' problems; but regular meetings together with representatives from a variety of functions may be more valuable. OR involvernent in quality circle programmes is a step in this direction. Lemaitre and Stenier identify the importance of outside sources of ideas (clients, suppliers, competitors, universities), and the value of systematically analysing failures. Although cultivating a willingness to admit to failure may be difficult, it is a prerequisite to learning how to avoid past mistakes. Significantly (for operational researchers), Lemaitre and Stenier found that it is much more effective for top management to act as a catalyst in creating a context which encourages creativity and risktaking, rather than to propose ideas for innovation and delegate the development to lower echelons. In the specific group of technical innovations studied, Lemaitre and Stenier found that all of the projects initiated at the top level led to failures. One reason for this was top management's tendency to overestimate the capabilities of lower echeions or underestimate the difficulties associated with the project. They conclude that the role of top management is not so much to have ideas themselves. as to help the staff members give birth to theirs. For management the problem is not to find the right answers, it must perceive and ask the right questions. In many ways the OR group is in a similar position to top management with regard to its perspective and distance from operating levels. The implication is that OR may have a dual role: raising issues and asking questions on the one hand; but also seeking ideas from outside the organization, and systematically appraising past mistakes within the organization.

\section{Conceptualization}

The conceptualization stage involves refining an idea and obtaining support for it amongst colleagues and relevant parts of the organization. This may require significant negotiating skills and is facilitated by an organizational environment which encourages communication and co-operation both vertically and horizontally. At this stage, Lemaitre and Stenier argue for comprehensive assessment of the resources needed to develop the innovation and resources available in the organization. This analysis should cover technical aspects (equipment, skills, know-how), commercial aspects (user characteristics and expectations), and organizational aspects (in-house procedures and structures affected by the the proposed innovation). Burgelman recommends evaluation of the strategic importance of the idea and an evaluation of the compatibility of the proposed innovation with the organization's operational structure and abilities. Lemaitre and Stenier found that inadequate analysis of resources in this phase was one of the basic factors which caused several projects they studied to fail. Inadequate analysis was frequently due to complacency regarding the amount of resources available to the innovator, or excessive focus on only one aspect of the project with which the innovator happened to be familiar. Operational researchers should also note that deficient analysis here may not keep a project from making headway, but contributes to later failure when technical infeasibility or inadequacy of resources finally becomes apparent.

Important factors to consider in the development and operationalization stages cited by Lemaitre and Stenier are factors well recognised by operational researchers: autonomous, clearly-defined units dedicated to achieving the innovation, support from top management to protect innovative effort, frequent checking with possible users to demonstrate technical feasibility, ability of the organization to adapt operating procedures to accommodate the innovation, and adequate preparation of users by undertaking information and training campaigns.

The innovation literature offers a number of ideas to OR groups seeking to become more innovative themselves and hence (even) more effective. In addition, OR groups can reinforce the innovative capacity of their parent organizations by the nature of the projects they undertake. For example, one of Lemaitre and Stenier's three main recommendations is that firms must develop methods to improve forecasts of their internal and external environments. This is not merely a matter of improving short-term, extrapolative forecasting techniques, but a need for coherent, long-term forecasts using the established methods of futures research. I am aware of at least one OR group that successfully sought involvement in major strategic issues of the parent company by investing effort in long-term scenario studies of the firm's future business environment. This was an innovative approach in the group's way of working, and also for the company; but the benefits to both company and OR group were substantial.

\section{STEPHEN WARD}

\section{For the interested reader}

Burgelman, R.A. (1986): Inside Corporate Innovation: Strategy, structure and Managerial Skills, The Free Press, New York.

Henry, J. and Walker, D. (Eds) (1991): Managing Innovation, Sage Publications, London

Lemaitre, N. and Stenier, B. (1988): "Stimulating innovation in large companies: Observations and recommendations for Belgium", R\&D Management 18 (2), pp. 141-157.

Marquis, D.G. (1969): "The anatomy of successful innovations", Innovation Magazine, November, pp. 28-37

Quinn, J.B. (1985): "Managing innovation: Controlled chaos", Harvard Business Review, May-June. 